\title{
BEST Robotics Practices
}

\author{
Li-Jen Shannon
}

\begin{abstract}
To attempt to overcome the gap of performance in science, technology, engineering, and mathematics performance inUS, the Boosting Engineering Science Technology Robotics Inc. designed the BEST Robotics Competition events to promote engineering writing skills, critical thinking skills, and teamwork to promote robotics design and marketing competencies. This BEST Robotics practice has becoming a trend to be included in the curriculum of middle and high schools.
\end{abstract}

Index Terms - Curriculum design, robots, STEM.

\section{BACKGROUND AND HISTORY}

The fact that the U.S. students lag behind in math and science performances continues to be a burning issue for the nation. In the past decade, although ample studies offered a significant variety of fun computing projects to motivate students in math and science learning, this issue has been disregarded. This may be attributed to a misaligned curriculum, or perhaps due to educators who lack the required technical skills. Furthermore, the minority students who are interested in the Science, Technology, Engineering, and Mathematics (STEM) fields are continuously decreasing. To attempt to overcome these issues, many robotics programs were introduced to the elementary and secondary schools. The experimental robotics curriculum was proved as effective at teaching youth about science, engineering, and technology concepts like computer programming, robotics, mathematics, and engineering [1]. Ebelt also showed that the young students' attitudes toward STEM, problem solving and teamwork indicated an increased interest [2]. Han, Jones, and Jo found that the youngsters showed a significant higher and steadier score on the factors of concentration, interest, and achievement when comparing using robotics program with other educational media [3]. Moreover, Mubin, Stevens, Shahid, Mahmud, and Dong believe that not only are robots built on advanced technology but they also provide a tangible and physical representation of learning outcomes, such as a valuable aspect of employing them in education [4].

Along with the robotics curriculum movement in US, BEST (Boosting Engineering Science Technology) Robotics Inc. (BRI) designed a BEST Robotics Competition for middle and high school students (from 7th to 12th grade), to promote engineering writing skills, critical thinking skills, and working with teams on robotics design and marketing strategies. Since 1993, when the very first BEST Robotics Game was held, there have been 53 hubs from 19 states sponsoring the BEST events. BRI is a non-profit and volunteer-based organization. The volunteering hubs are

Manuscript received February 10, 2014; revised April 10, 2014.

Li-Jen Shannon is with the Computer Science Department, Sam Houston State University, USA (e-mail: lys001@ @ shsu.edu). organized by local community colleges, universities, or a group of people who are motivated to promote STEM. In spring 2013, the positive impacts from the BEST Robotics competitions were recognized by the STEM Team for US President Obama. However, due to the nature of volunteerism as the foundation of BEST Robotics Competition, no formal research projects from the BEST organization have been studied and/or published to support the significant impacts on the students' career paths and interests in STEM fields.

In 2011, our local SouthEastTexas BEST Hub in Sam Houston State University (SHSU) was established to recruit schools around the rural areas. In the past three competition seasons at SHSU, we have brought in 20 to 24 teams each year with approximately 800 participants in the Johnson Coliseum. Each fall, over 850 middle and high schools and over 18,000 students participate in the competition nationally. Over 3,500 volunteers have been helping the local competitions and regional championships by serving as event personnel, judges, and team mentors. We have learned that BEST Robotics events have become a needed curriculum and tradition among the veteran-participated schools. However, we also witnessed that a well-designed teacher training program and team mentoring program definitely make a vital difference in ensuring the success of participating teams. Many studies echoed that a lack of high quality STEM teachers is the top reason why minorities and women were less likely to have interests in STEM fields [5]-[8]. Saerbeck, Schut, Bartneck, \&Janse showed a clear positive effect of how the robotic tutor (educator) impacted the learning outcomes by providing the role model, non-verbal feedback, attention guiding, empathy and communicativeness [9]. Thereafter, this paper is to showcase the evolution of how our BEST practices developed in research and mentoring to assist in STEM fields.

\section{BEST INTRODUCTION}

In the past decade, there have been many institutions, educational agencies, and for non-profit organizations establishing robot training program for high schools, community colleges, and universities. They offer the opportunity for learners to utilize the latest automation technology while applying STEM. Just name a few of the programs, such as, ABB power and automation technologies training programs [10], FANUC certified education robot trainings [11], Carnegie Mellon professional development in robotics academy [12], and National Robotics Training Center [13]. These professional development programs provide networking opportunities with professional educators while the learners were trained to use hardware and software, build up a solid foundation for robot programming, and experience in troubleshooting. Moreover, these programs have been working on needs assessment to adjust their 
program development process [13].

The BEST Robotics Competition has becoming a significant program which is adopted by many schools in US. The main attraction from the BEST program is to provide a 100 percent hands-on learning environment for the students with no cost for the school. Regardless of socioeconomic status, size, or location, any public, private, home school or organizations are welcomed to participate. The students take plywood, fiberglass board, metal sheet, and a box which is filled with raw materials, such as PVC pipes, screws, valve cover, piano wire, aluminum paint grid, a bicycle inner tube, rollerblade rollers, duck tapes, and a micro-energy chain system. Within six weeks of official time frame started in each early September, the student-team design and build a functioning remote-controlled machine that would perform specific game tasks in three minute per match [14]. The students are the primary participants and benefactors. The mentors, coaches, or teachers can only serve as guides and advisors. For the subsequent sections, "coach" will be applied and defined as a teacher who is to lead the robotics developmentin the robotics teams. The students must perform all of the work on their own. Engineers and other professionals from local industries are invited to serve as team mentors. Each year the game theme was designed two or three years ahead of scheduled game year by a group of Game Committee which is comprised by volunteering engineering staff. The game theme is rotated in the subject matters of biology, chemistry, computer science, technology, and other combined engineering and science fields.

The mission of BEST is to engage and excite students about engineering, science, and technology as well as inspire them to pursue careers in these fields. Each year, the game theme is kept in a secret until the Kickoff Day to start the six weeks' challenge. The students must conduct research about the game theme in order to provide a thorough engineering notebook to analyze and solve problems by implementing the Engineering Design Process. Moreover, this engineering notebook process will help the students to develop technological literacy skills which will fulfill the needs from the workforce.

\section{Best Robotics Competition Events}

BEST Robotics Competition is not just for robots. It's designed for the students exploring their interests in many fields by working with a team. They can focus and/or try out their talents in the following events: Creative Design, Engineering Notebook, Marketing in Oral Presentation, Marketing in Exhibit and Web Design, Sportsmanship, and Robotics Game. Generally, a team would be comprised with groups of students who have similar interests and expertise to work together for the sub-tasks. For example, a group of engineering students who understand the math concepts and applied physics; a group of artistic students who are responsible for the creative design for robust robots; a group of marketing students who promote their design-to-market development. However, each school or team is not required to compete all of the events. The only two mandatory events are Engineering Notebook and Robotic Game. If any school or team would like to earn a Best in BEST Award, all of the events will be required.
The software provided for the schools are included but not limited to: Programming software of MathWorks, EasyC, and Robot C; Computer Aided Drafting software of SolidWorks, and HSMWorks; Training programs offered by InspirTech; Computational Tool of Wolfram Mathematica; Control System provided by VEX; and donation products from igus products. Many founding partners from the list above provide excellent tutorial materials to mentoring the team's learning process.

\section{BENEFITS FOR THE STUDENTS}

With the available tools BRI provides to each team, the students are able to try out various software and programs to design their robots in a most efficient way. For a newly joined team, most of them started with Easy $\mathrm{C}$ as the main programming to build their control system with VEX. After few years of practices, the veteran teams advanced their learning into Robot $\mathrm{C}$ or even MathWorks. This provides the opportunities to train our Computer Science students as the BEST programming mentors.

For the designing and drafting procedure, the teams are able to use SolidWorks, and/or HSMWorks to create a 3D platform and simulate their robot to foresee the possible issues before they actually cut the raw materials and build their robots. Along with their engineering design process, mentors have played a significant role to assist in the teams' success and safety. Safety Training was one of the most important sections in our Kickoff events. Safety googles, safety rules, and appropriate behaviors in the lab were strongly emphasized for the teams. Each participated student must receive Safety Training and have the parents' consent signature before the student could operate the power tools and build a robot.

The unique design of BEST Robotics Competition is to offer the students who are not engineering oriented, but would like to participate in supporting the team product. One of the competition events, Oral Presentation and Marketing Display would provide the network for those students to use their creativity in designing marketing materials, such as brochures, Web site design, exhibition display, and oral presentation in front of judges. This event offers an outlook of how each object around them is related to multi-disciplines and functions.

The BEST robotics practices provide the channel for the students to look at STEM from a different dimension. Through this BEST program, they had real-world engineering experience with industry professionals and mentors. From years of participations, we witnessed how the veteran students have been outgrowing in their abstract thinking, self-directed learning, problem-solving skills, and leadership skills. These competencies are what their future workforce employers looking forward to as the asset of their companies. The participated students were motivated and believed in that they could make their dream come true if they tried.

\section{Mentoring Program}

\section{A. Team Retention}

Learning all of great benefits as the bi-products of BEST 
Robotics participation from the section above, we are still facing the challenge of losing some new teams or new coaches for the following seasons. There has been a high turnover rate among the low performance school districts or small size schools. Each year, we recruited $40 \%$ of new teams with new coaches to sign up and participate in the six week game preparation events. Unfortunately, a quarter of those new teams either couldn't complete the tasks, or the coaches were overwhelmed by their loads and gave up on leading the teams to the completion dates. In the past three years' practices in hosting the game events, we witnessed how some similar factors were showed among those returning veteran teams. And the factors of losing teams had emerged before dropping out from the competition rosters.

The typical school teachers are expected to accept and fulfill numerous roles while they serve on campus. The robotics team coaches generally carry more loads than other teachers do to practice on balancing their duties and leadership skills. In this technological fast-changing society of the 21st century, the coaches themselves have to continuously update their knowledge and moreover, they have to lead the team to learn more new software and applications regarding to robotics operation. The coaches have the desire to integrate the robotics software into their curricular areas. They would like to play the roles as the subject expert to lead their teams into a successful competition season. However, for most of the newbies, they faced a challenge of struggling with the timeframe, workload, and task management. Therefore, the coaches must be ready to act as leaders to provide the available technologies and encourage a participatory culture.

\section{B. Mentoring Assistance}

In the past seasons, we started to implement a mentoring program to assist in teams' project development and management. We had mentors voluntarily prepared to review several areas, including mechanical design, engineering notebook records, robotics programming, and general issues. By the deadline of turning in team robots, we found that the teams drop out from the competition were the teams which did not take the advantage of having our mentors visited their campus and review their project progress. Our mentoring program was to offer a more experienced individual who could provide counsel, guidance, and assistance to the teams. Ghosh (2013) studied the mentoring conception from several literature reviews and defined the mentoring in education as to focus on the nature of a mentoring relationship which is dynamic, interactive, personal, reciprocal, and collaborative leading to growth for both the mentor and the protégé [15].

Besides of building a mentoring relationship, practicing leadership would be a vital element to make a success for the teams. Johnston (2013) stated that mentoring has been recognized as a critical component in leadership development, and effective mentoring is essential to the growth and success of the program. In the area of technology integration, mentoring through professional organizations has emerged as an important factor in enabling leadership[16]. As educators, we all look for ways to cultivate and develop leaders. No matter the targeted person for the mentors would be the coaches or the team members, people and interpersonal relationships is one of the most frequently occurring enabler facilitating accomplished the leader's efforts in leadership
[16]. Johnston emphasized on the importance of professional organizations as providing a network of fellow to learn from and share with as an enabler for interacting leadership in technology integration.

Broadbent and Papadopoulos (2009) assessed their practices among community education and youth mentoring which focused on individuals being matched to adult mentors and subsequent role models [17]. They found the factors to run a successful mentoring program, including a supportive and active steering committee or reference group; organizational support; program coordinator skills, attributes, and experience; strong relationship with mentee referring organization; networking; funding; committed and supported mentor; and program model. These factors clearly reflect on what we had experienced with our teams. Thereafter, a mentoring program has been designed to address and overcome the issues which each team might encounter with. The framework of our Mentoring program will be defined in the following section.

\section{Mentoring Program Framework}

\section{1) A supportive and active steering committee}

This committee is comprised with a minimum of three volunteers who have the experiences in the operation of BEST Robotics Competition events. Each committee has his/her expertise in certain areas to provide the Mentoring Training materials and guidelines by utilizing related contacts and networks.

\section{2) Organizational support}

The needed support would be weaved by three entities which one is the hosting organization, another is the team school, and the other is the BEST Inc. With the supports from each link, the supportive staff will be able to manage the mentors' duties and produce a success outcome.

\section{3) Program coordinator credential}

While technology evolves rapidly, the program coordinator is responsible of updating the skills and attributes. BEST Inc. provides workshops, trainings, and webinars all year round, the program coordinator will be able to earn the updated knowledge of service sector in order to provide the needed professional development and succession planning for the mentors and coaches.

\section{4) Strong relationship with mentee referring organization}

A strong partnership between the team schools and the hub organization will make it possible to have a long-term retention. To promote the cooperative partnerships, a two-way communication will be reinforced to achieve the goals for both entities.

\section{5) Networking}

Social networks have been created to invite the participation from the teams. Blogs and online resource sharing center are available for the mentees to review and post questions. Another benefit of using social networks is to extend the peer supports from the face-to-face meeting to the online forums.

6) Funding

BEST Robotics Competition is free of charge for each team. Therefore, the needed funding would be applied only 
for the teams which would like to increase their team spirit events by ordering uniforms and building exhibition boards for displaying their hard work. Therefore, fund raising events will be encouraged to ask for their local support. Many veteran teams already build a foundation with local businesses and earning individual sponsorships. A plan set up for corporate support and local sponsors would be strongly encouraged within the mentoring program.

\section{7) Committed and supported mentor}

With a successful recruitment for mentors, it still might end with few committed and supported mentors left at the end of the season. Just like the coaches' positions, the mentors have their regular job and duties to fulfill in their daily life. Therefore, the careful screening and selection would be vital to match the right groups of teams for each mentor. A timely training to ensure the mentors' learning outcomes will also play a key element to retain responsible mentors. The mentor network increases the effective outcomes of serving the teams to support what the mentors learned in the training program.

\section{8) Program model}

Some BEST hubs host around 10 teams per year. And there are few BEST hubs host around 40 teams every year. It is definitely positive that a well-designed mentoring program has been playing a successful role for those hubs which are able to retain the teams and continuously increase the size of their service areas. A further investigation in modeling their success would be the crucial step for us to follow.

\section{CONCLUSION}

In an effort to recruit more minority participants and low-performing schools, we have been working on establishing research and mentoring programs to assist in BEST Robotics competition in the past years. We understand that this six-week robotics program seems to be overwhelming for any new team with new coaches. Therefore, we offer multi-sections of Face-to-face Teacher Training Workshop, as well as online Teacher Training Workshop in summer before the season kicks off to provide the guidelines for the participated teams. The international season requirement is to complete the competition day by the end of Octobers. Counting six weeks back from the competition day, it doesn't leave too much room for the coaches to recruit students joining the team in fall semester. Therefore, our recruitment plan has been pushed to spring semester before the summer starts. The available curriculum and lesson plans are in place for the schools to review and adopt for either after school program or course work which can be incorporated into their Physics, Pre-Engineering course or Robotics course. This will offer a longer timeframe for the coaches to digest and plan ahead of what they could manage when the season kicks off in fall.

On the other hand, the negative side of recruiting new teams and coaches in spring semester is that the coaches might relocate to other areas or their teaching roles and loadshave been changed in fall semester. For the teams experienced this kind of incidents, the Mentoring Program will be a big release to support the last minute assigned coaches. When the students comprehend the challenge ahead of them by creating a robot in six weeks, either the students will be motivated to organize the tasks to fulfill their goals on time, or the students might lose their interest and let the new coaches to drag and push their progress. To prevent any possible drawback occurred, our Mentors would need to step in ahead of time to connect with the students and school administrators.

Along with the Teacher Training Program, we recruited a mentoring team which is comprised by local professionals and university faculty. Each mentor has his/her expertise in engineering design process, mechanical operation, computer-aided drafting, robotics programming, marketing and business. The mentoring team will complete a training program which covers the prototype of the game theme, rules, programming, engineering design, and general guideline. Each mentor will be assigned to three to four teams. During the six weeks' game design process, each mentor will visit each assigned team in a weekly base to guide the team going through their troubleshooting and re-evaluating stages.

This practice has been leading our research direction to prepare for grant proposals for Summer Enrichment Program Grants, Robotics Mentoring Program, and Undergraduate Research Projects in the following coming years. Moreover, the BEST Inc. and hubs from various states (Alabama, Arkansas, Colorado, Louisiana, New Mexico, Tennessee, \& Texas) agree to participate in a large scale of research project through the federal grant. We would like to encourage the participation from any international country. The future research findings and outcomes will be published to support the efforts which have already been recognized by US President Obama's STEM Team.

The employment of computer and information research scientists is projected to grow faster than the average for all occupations in the next two decades [18]. In addition, the job outlook will be driven by advanced robots which already been used widely. To meet the increase demanding job markets, the BEST Robotics Competition acts on the first step by opening the discovery door to allow the middle and high school students explore in this robotics world.

\section{REFERENCES}

[1] B. S. Barker and J. Ansorge, "Robotics as means to increase achievement scores in an informal learning environment," Journal of Research on Technology in Education,vol. 39, no. 3, pp. 229-243, 2007.

[2] K. R. Ebelt. (2012). The effects of a robotics program on students skills in STEM, problem solving and teamwork. Montana State University. [Online]. Available: http://scholarworks.montana.edu/xmlui/bitstream/handle/1/1216/Ebelt K0812.pdf?

[3] J. Han, M. Jo, V. Jones, and J. H. Jo, "Comparative study on the educationaluse of home robots for children,"Journal of Information Processing Systems, vol. 4, no. 4, pp. 159-168, 2008.

[4] O. Mubin, C. J. Stevens, S. Shahid, A. A. Mahmud, and J. Dong, "A review of the applicability of robots in education," Technology for Education and Learning, vol. 1, pp. 1-7, 2013.

[5] Bayer Corporation. (2010). Bayer facts of science education XIV: Female and minority chemists and chemical engineers speak about diversity and underrepresentation in STEM. [Online]. Available: http://www.igert.org/system/content_item_assets/files/579/Bayer_Fac ts_of_Science_Education_Executive_Summary.pdf?1269877505

[6] B. Howare-Brown and D. Martinez. (2012). Engaging diverse learners through the provision of STEM education opportunities. SEDL. [Online]. Available: http://secc.sedl.org/resources/briefs/diverse_learners_STEM/

[7] National Science Foundation. (2011). Women, minorities, and persons with disabilities in science and engineering: 2011. NSF 11-309. 
Arlington. VA: Author. [Online]. Available: http://www.eric.ed.gov/PDFS/ED516940.pdf

[8] President's Council of Advisors on Science and Technology. (2011). Prepare and inspire: $\mathrm{K}-12$ education in science, technology, engineering, and math (STEM) for America's future. [Online]. Available:

http://www.whitehouse.gov/sites/default/files/microsites/ostp/pcast-st em-ed-final.pdf

[9] M. Saerbeck et al., "Expressive robots in education - varying the degree of social supportive behavior of a robotic tutor," in Proc. the 28th ACM Conference on Human Factors in Computing Systems, Atlanta, 2010, pp. 1613-1622.

[10] ABB. (2013). [Online]. Available: http://www.abb.com/product/us/9AAC128749.aspx?country=US

[11] FANUC (2013). [Online]. Available:http://www.fanucrobotics.com/support-services/robotics-tra ining/CERT.aspx

[12] Carnegie Mellon Robotic Academy. [Online]. Available:http://www.education.rec.ri.cmu.edu/content/educators/prof essional_dev/

[13] National Robotics Training Center (NRTC). (2013). [Online]. Available:http://www.nrtcenter.com/Training/

[Online].

[14] BEST

(2013).

Available:http://bestinc.org/documents/Competition\%20Overview.pd $\mathrm{f}$

[15] R. Ghosh, "Mentors providing challenge and support: Integrating concepts from teacher mentoring in education and organizational mentoring in business," Human Resource Development Review, vol. 12 no. $144,2013$.

[16] M. P. Johnston, "The importance of professional organizations and mentoring in enabling leadership," Knowledge Quest, vol. 41, no. 4, pp. 34-39, 2013

[17] R. Broadbent and T .Papadopoulos, "Community education and youth mentoring: How to build good practice?" Australian Journal of Adult Learning, vol. 49, no. 2, pp. 318-351, 2009.
[18] Computer and Information research Scientists. (2014). Occupational Outlook Handbook.[Online]. Available: http://www.bls.gov/ooh/computer-and-information-technology/compu ter-and-information-research-scientists.htm\#tab-6

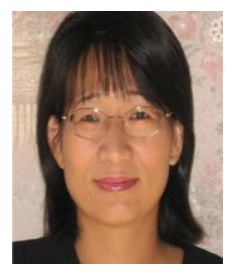

Li-Jen Shannon earned a master degree in industrial technology in 1995 and Ed.D. in higher education executive leadership in 2007 at Sam Houston State University, Huntsville, Texas, USA

Since 2007, she has been teaching instructional technology master program in the Department of Computer Science at Sam Houston State University, Huntsville, Texas. Prior to teach the master degree program, she was a lecturer teaching A+, CCNA, Computer Networking, MCSE, Introduction to Computers, and Multimedia Technologies in the Department of Technology and the Department of Computer Science at Sam Houston State University from the year of 2000 to 2006. She is an Assoicate Professor at the Department of Computer Science and also serves as the Director of SouthEast Texas BEST Hub. In the past six years, she published 2 books, 18 journal papers, and presented at 23 national and international conferences. Areas of research interest include computer and technology curriculum alignment from secondary to graduate levels, educational multimedia research, and international technology development in education.

Dr. Shannon served as the board member of Education Special Interest Group (EDSIG) and Association of Information Technology Professionals (AITP) from the year of 2009 to 2012. She is the editorial review board member for Journal of Information Systems Education (JISE) \& Journal of Computer Information Systems (JCIS). She received awards including Best Paper, Distinguished Paper, Meritorious Paper, and Outstanding Paper from the Information Systems Educators Conference and General Business Conference. 